became epitomized in the therapeutic community movement. We played an important part in the evolution of social psychiatry which helped us to see the importance of social ecology and the lessons we must learn from nature. These liberal qualities then became confluent with the social evolution in the Western countries beginning in the 1960s and is still gaining momentum. As Capra, a distinguished physicist, points out, we seem to have reached a 'turning point' where the familiar reductivist scientific approach to learning and growth is being implemented by an integration of Eastern and Western cultures and a new conceptual framework for economics, technology, physics and medicine.

In a more specifically Western context, there are numerous cultural movements including environmentalists, feminists, consumer advocates, peace movements and many others. Part of this changing climate of public opinion is the growing disenchantment with the abuse of authority by the professions such as law and medicine and by government generally. In this context, politicians seem to be more concerned with the retention of power than with societies' individual needs. If we consider a hospital to be a microcosm of society, then a therapeutic community is associated with all the foregoing problems of social structure, decentralization, information sharing and shared decision-making at all levels of the social organization from patients to governing bodies.

In the therapeutic community movement we have come to have a deep distrust of reductivism in the form of scientific research unless it is linked with a humanistic orientation and subject to constant discussion and recycling with a view of achieving consensus with all the participants. We are not afraid of social values which highlight morality and the need to keep a constant check on the abuse of power. We evolved a democratic system which inevitably clashed with the more authoritarian and technocratic systems in other psychiatric facilities and in our surrounding environment, dominated by professional tradition, rationalism, and secularism.

At the same time, we became conscious of the effects resulting from our change from an individualistic society to one with a group identity. We began to experience new strength and a feeling of security which was badly needed to combat the constant attempts to liquidate us which came from our own profession. This empathy amongst staff and patients was the start of a growing synergism and we began to comment on our feeling of fulfilment which at first as individuals we were at a loss to explain. We even dared to recognize a growing spirituality which helped us to explore new dimensions of consciousness such as intuition and the motivating driving force. Our group consciousness and open system organization seemed to have something more than the aggregate wisdom of a number of people with their individual inputs and good will. In effect, it was synergistic and creative.

It is in this context that the therapeutic community has relevance. Its survival as a model for change, its positive healthy effect on the people involved, its answer to the abuse of power by delegation of responsibility and authority to the level in the system where it belongs, its conceptual framework of multiple leadership, social learning, growth and creativity reflects one approach to the cultural dilemma of our time. The general principles worked out in a microcosm of society, a hospital, can be applied to all levels of our cosmic society if adapted to the culture and social environment as required. It has taken me forty years to arrive at this point as one individual with, I hope, many peers who epitomize this spirit of change which seems to grow daily everywhere. Can the gradual metamorphosis to holism be speeded up in time to prevent an atomic holocaust or famine on a world scale?

\section{The Lynda Bateman Award for the Alleviation of Epilepsy}

The Lynda Bateman Fund announces the establishment of an annual or biannual prize of approximately $£ 1,000$ to the person or persons who have, during the period under consideration, made a significant contribution to the understanding, prevention, cure or management of epilepsy. The award is open to anyone working in the United Kingdom in the field of epilepsy. Work in both the clinical sphere and the basic sciences will be considered. Interested applicants should submit evidence of their work to the Trustees and this will be placed before a panel to be nominated by the Institute of Psychiatry. The first prize will be awarded in 1985 and submissions should be received by 1 November 1984. Further details may be obtained from the
Lynda Bateman Fund, 34 St Martin's Approach, Ruislip. Middlesex (telephone Ruislip (08956) 38295) or from the Dean of the Institute of Psychiatry, De Crespigny Park, London SES (telephone 01703 5411).

\section{Louis Marce Research Award}

The Marce Society is an international scientific society formed to advance the understanding, prevention and treatment of mental illness related to childbearing. A prize of $£ 250$ is offered for the most important initiative in education and/or research promoting the aims of the Society. For further information contact: Dr F. Margison, Consultant Psychotherapist, Department of Psychiatry (MRI), Gaskell House, Swinton Grove, Manchester M13 0EU. 